\title{
Redes de apoio social em comunidades rurais do Maranhão: mulheres construindo o desenvolvimento local sustentável
}

\author{
Neuzeli Maria de Almeida Pinto \\ Programa de Pós-Graduação em Desenvolvimento Socioespacial e Regional / Universidade Estadual do \\ Maranhão (PPDSR/UEMA) \\ Josilene Montelo Ferreira
}

Secretaria de Educação do Estado do Maranhão (SEDUC/MA)

Recebido: 21/02/2019 Versão revisada (entregue): 28/04/2020 Aprovado: 19/05/2020

\begin{abstract}
Resumo
Este artigo examina o papel das redes de apoio social mantidas por mulheres em comunidades rurais do Maranhão, e o modo como se organizam para fins de estruturação de relações sociais familiares, autonomia e empoderamento na construção do desenvolvimento local sustentável. A pesquisa foi realizada na região da Baixada Maranhense e do Litoral Ocidental Maranhense, nas comunidades de Agrovila/Palmeirândia e Itamatatiua/Alcântara, respectivamente. Para esta análise foram utilizados os instrumentos metodológicos: diário de campo, inventário sóciodemográfico e entrevista semiestruturada. O estudo identificou que as redes de apoio social se organizam por meio de sistemas comunitários de trabalho. Essas experiências contribuem para o desenvolvimento local sustentável, para a presença das mulheres nos movimentos sociais e para o seu empoderamento. Apesar dos projetos de desenvolvimento comunitário, as famílias ainda permanecem em situações de vulnerabilidade social. A pesquisa concluiu que este trabalho pode ser útil na proposição de políticas públicas e propostas de ações comunitárias em bases democráticas e sustentáveis.
\end{abstract}

Palavras-chave | Desenvolvimento local sustentável; Maranhão; mulheres; rede de apoio social; trabalho rural.

Código JEL | I31 J16 Q57

Social support networks in rural communities of Maranhão: women building sustainable local development

\begin{abstract}
This article examines the role of social support networks maintained by women in rural communities in Maranhão and the way they are organized for the purpose of structuring family social relationships, autonomy and empowerment in building sustainable local development.
\end{abstract}


The research was carried out in the region of Baixada Maranhense and the Western Coast of Maranhão, in the communities of Agrovila/Palmeirândia and Itamatatiua/Alcântara, respectively. For this analysis, the daily field methodological instruments (DC), sociodemographic inventory (ISD) and semi-structured interviews (ESE) were used. The study identified that social support networks are organized through community work systems. These experiences contribute to sustainable local development and the presence of women in social movements and empowerment. Despite community development projects, families still remain in situations of social vulnerability. The research concluded that this work can be useful in proposing public policies and proposals for community actions with democratic and sustainable bases.

Keywords | Maranhão; rural work; social support network; sustainable local development; women.

JEL-Code | I31 J16 Q57

\section{Redes de apoyo social en comunidades rurales de Maranhão: mujeres construyendo el desarrollo local sostenible}

\section{Resumen}

Este artículo examina el papel de las redes de apoyo social mantenidas por las mujeres en las comunidades rurales de Maranhão, y la forma en que se organizan con el propósito de estructurar las relaciones sociales familiares, la autonomía y el empoderamiento en la construcción del desarrollo local sostenible. La investigación se llevó a cabo en la región de Baixada Maranhense y la costa occidental de Maranhão, en las comunidades de Agrovila/Palmeirândia e Itamatatiua/Alcântara, respectivamente. Para este análisis, se utilizaron como instrumentos metodológicos: diario de campo (DC), inventario sociodemográfico (ISD) y entrevistas semiestructuradas (ESE). El estudio identificó que las redes de apoyo social se organizan a través de sistemas comunitarios de trabajo. Estas experiencias contribuyen al desarrollo local sostenible, para la presencia de mujeres en los movimientos sociales y para su empoderamiento. A pesar de los proyectos de desarrollo comunitario, las familias aún permanecen en situaciones de vulnerabilidad social. La investigación concluyó que este trabajo puede ser útil para proponer políticas públicas y propuestas para acciones comunitarias con bases democráticas y sostenibles.

Palabras clave | Desarrollo local sostenible; Maranhão; mujeres; red de apoyo social; trabajo rural.

Codigo JEL | I31 J16 Q57

\section{Introdução}

As redes de apoio social de mulheres rurais nas regiões da Baixada Maranhense e Litoral Ocidental Maranhense, nas comunidades de Agrovila/Palmeirândia e 
Itamatatiua/Alcântara, respectivamente, têm contribuído para a construção do desenvolvimento local sustentável, o qual se efetiva por meio do trabalho coletivo e cooperativo da produção de peças artesanais de cerâmicas e da produção agrícola, baseada na agricultura familiar. Essas redes de apoio se transformam em instrumentos de desenvolvimento local sustentável a partir de uma prática que articula aspectos econômicos, culturais e ambientais. Além disso, asseguram dentro dos dois grupos comunitários a existência dessas agricultoras como membros da comunidade, com base no trabalho conjunto, na posse comum dos meios de produção, na partilha coletiva, recíproca e solidária por meio das associações comunitárias.

Esta pesquisa se classifica como estudo de caso de caráter qualitativo, cujo objetivo é entender a composição e o funcionamento das redes de apoio social de mulheres, levando em consideração as questões de gênero, trabalho e desenvolvimento local sustentável. As análises realizadas foram feitas de acordo com o contexto de mulheres inseridas em processos cooperativos e solidários. Participaram da pesquisa 15 mulheres trabalhadoras rurais de duas comunidades, Itamatatiua/Alcântara e Agrovila/Palmeirândia que desempenham atividades relacionadas ao trabalho rural e participam de movimentos da associação comunitária das comunidades, sendo que as mulheres de Itamatatiua exercem trabalho de artesanato de cerâmica.

Os instrumentos metodológicos utilizados que deram respaldo à pesquisa qualitativa foram o diário de campo (DC), utilizado com a finalidade de obter e registrar aspectos ecológicos pertinentes às análises, bem como os dados recolhidos suscetíveis de serem interpretados. Também se utilizou o inventário sociodemográfico (ISD), que abrange 45 itens, cujos aspectos serviram para pontuar não somente as características da comunidade nos contextos recortados, mas, também, as particularidades das familias, as quais foram utilizadas como critérios de seleção, tais como características estruturais e organizacionais. Por fim, a entrevista semiestruturada (ESE) foi utilizada para recolher dados descritivos na linguagem do próprio sujeito e permitindo ao investigador o desenvolvimento intuitivo de uma ideia sobre a maneira como os sujeitos interpretam aspectos do mundo.

A Baixada Maranhense, um dos lócus da pesquisa, é uma microrregião de rica composição de campos naturais e de lagos perenes e sazonais. Possui a criação de gado bubalino por grandes fazendeiros, o que contribui para o acirramento de conflitos fundiários na região. O próprio cercamento dos campos públicos tem como consequência a diminuição drástica da pesca, além da degradação ambiental, processos que remontam à prática institucionalizada da grilagem em terras públicas. Segundo Barbosa (2006), a implantação do capital produtivo nas grandes fazendas no Maranhão resultou do açambarcamento de grandes extensões territoriais antes ocupadas por posseiros e camponeses. 
A região apresenta características geográficas específicas, com obstáculo natural para a mobilidade e acessibilidade física de seus moradores, além de sérios entraves para a comunicação e o escoamento da produção. O conjunto da população convive com um modelo de desenvolvimento excludente e baixos índices de desenvolvimento humano. Com precárias condições de acesso à infraestrutura e serviços públicos, a microrregião da Baixada Maranhense é composta por 21 municípios e uma população eminentemente rural (IBGE, 2015).

A comunidade de Agrovila, localizada no município de Palmeirândia, é um assentamento rural com cerca de 800 famílias que vivem da agricultura de subsistência e de uma pequena comercialização de produtos agrícolas como arroz, feijão, milho, mandioca, maxixe, frutas e verduras. A Associação de Mulheres Agricultoras reúne grande capacidade de articulação política, tendo já participado por quatro vezes da "Marcha das Margaridas"1, compõe o sindicato dos trabalhadores e trabalhadoras rurais, e desenvolve atividades de inclusão, recreação e esportes, destinadas ao maior envolvimento das mulheres da comunidade.

Outra região que faz parte da pesquisa, o Litoral Ocidental Maranhense, corresponde ao segmento do litoral das reentrâncias maranhenses. Essa região está dividida em 13 municípios que se estendem da foz do rio Gurupi, a oeste, até a margem ocidental da baía de Cumã, a leste, tendo como limite a ponta do Guajuru, no município de Cedral (ANDRADE, 1969). A linha da costa das reentrâncias, dos municípios de Alcântara a Carutapera, foi estimada em $2.000 \mathrm{~km}$ de extensão. O município de Alcântara, onde se localiza a comunidade de Itamatatiua, possui uma população estimada pelo IBGE (2015) de 183.340 habitantes. Com uma área total de $9.557,592 \mathrm{~km}^{2}$, tem como principal característica a presença de manguezais, que são típicos de áreas litorâneas associadas ao encontro das águas dos rios com o mar, considerados berçários naturais, pois abrigam espécies típicas, como o vermelho - predominante, o siriba e o branco.

A comunidade de Itamatatiua é remanescente de quilombo. Diferente da história de muitos quilombos, ela não surgiu a partir de agrupamentos étnicos resultantes da fuga de escravos (GRIJÓ, 2008). Segundo Pereira Junior (2011), o quilombo também conhecido como Terra de Santa Tereza ${ }^{2}$ pertencia à ordem religiosa Carmelitas, que mantinha uma produção artesanal de artefatos cerâmicos, voltados

\footnotetext{
1 A Marcha das Margaridas, realizada desde o ano de 2000, é uma ação estratégica das mulheres do campo e da floresta que integra a agenda permanente do Movimento Sindical de Trabalhadores e Trabalhadoras Rurais (MSTTR) e de movimentos feministas e de mulheres. É um grande movimento de mobilização e organização das mulheres trabalhadoras rurais em todos os estados brasileiros, além de proporcionar uma reflexão sobre as condições de vida das mulheres do campo e da floresta. A marcha é um movimento de luta para romper com todas as formas de discriminação e violência, que trazem consequências perversas à vida dessas mulheres (SILVA, 2008).

${ }^{2}$ Santa que representa a igreja local e é considerada padroeira da comunidade e proprietária das terras entregues aos cuidados de um casal de escravos pela Ordem Carmelitas, antes de saírem da propriedade (relatos das mulheres de Itamatatiua).
} 
principalmente para a construção civil. Com a saída dos Carmelitas do território, os grupos étnicos que lá viviam permaneceram, construíram novas formas de relações e de trabalho. Contudo, a tradição do artesanato em cerâmica foi mantida pelas mulheres da comunidade, passando seus ensinamentos de geração a geração.

Atualmente, a comunidade tem, aproximadamente, 300 habitantes, os quais se dividem entre atividade artesanal, trabalho na roça, tarefas domésticas, além da prática da caça e da pesca para a subsistência. No entanto, o artesanato em argila, produzido pelas mulheres quilombolas, constitui-se na atividade econômica mais importante da região. Por mais de dois séculos essa prática tem sido a base do desenvolvimento local, proporcionando renda, melhoria nas condições de vida, trabalho e implementação de políticas públicas que beneficiaram a comunidade como um todo.

Tendo por base essas atividades, as mulheres cultivam práticas coletivas e cooperadas que fortalecem suas redes de apoio dentro das próprias comunidades, fator que amplifica quando se considera a cultura de sobrevivência dessas famílias. Existe uma participação ativa das mulheres nas atividades domésticas e no trabalho rural, organizados a partir de relações familiares que depois evoluem para formas mais amplas de participação. Essa participação promove a autogestão social, a qual se organiza por meio da associação de mulheres que desenvolvem um trabalho cooperado de artesanato em cerâmica, sendo essa a principal atividade econômica da comunidade no que se refere à produção e à comercialização.

Trata-se de considerar ainda a importância das redes de apoio social mantida pelas mulheres para a constituição de um arranjo social e econômico justo, equilibrado e duradouro das comunidades estudadas. As redes de apoio social também podem contribuir com a reorganização de maneira sustentável do bem-viver da comunidade, de modo que seja ecologicamente equilibrado e eticamente solidário.

\section{Para além da reprodução: o movimento de mulheres rurais}

As atividades laborais das mulheres dentro e fora do âmbito familiar tem sido objeto de discussão privilegiada na literatura recente sobre gênero. É importante ressaltar a distinção que existia entre as esferas das vidas privada e da pública, as quais correspondiam às esferas da família e da política, concebidas separadamente (ARENDT, 1995). Tal distinção implicava que a reprodução biológica e o trabalho voltado para a sobrevivência, inclusive o executado pelo chefe da família, devia ficar no âmbito do privado. Isso mudou no capitalismo, quando a produção, que é um processo cada vez mais social, revestiu-se da forma mercantil, mediada pelos atos de troca entre indivíduos privados. Almeida (2005), destaca o caráter fortemente ideológico dessa relação entre o público e o privado no capitalismo. 
Nesse contexto, o trabalho como atividade produtiva entra definitivamente na pauta dos estudos acerca da subordinação feminina. As mulheres são integradas ao mundo produtivo sem reduzir as suas responsabilidades domésticas, criando um conflito que se expressa nas intermitências laborais, na integração em setores ou ocupações mais precárias, e na maior vulnerabilidade em períodos de crise. Gerase, assim, um paradoxo, porque ao mesmo tempo em que o capital não pode prescindir da força de trabalho das mulheres, ele reforça o afastamento delas por meio de práticas discriminatórias e excludentes, como as altas taxas de desemprego e a informalidade mais elevada entre as mulheres (TEIXEIRA, 2008).

Assim, para o que nos interessa aqui, o esforço é o de tentar compreender como se reproduzem essas exclusões sociais no que se refere ao trabalho no meio rural. Implica pensar como esses grupos de mulheres geram alternativas de trabalho e renda mais inclusivas.

Esta pesquisa também identificou que, no contexto rural, a divisão sexual do trabalho é ainda mais assimétrica, pois os homens ainda exercem o papel de chefe da família e da propriedade. De modo geral, as mulheres (e de forma rotineira) são vítimas da discriminação no mercado de trabalho rural, pois são elas as responsáveis pela maior parte das atividades não remunerado. Esses fatores contribuem para uma não inserção na produção agrícola e no desenvolvimento rural (HEREDIA; CINTRÃO, 2006; SILVA, 1999).

Contudo, a atuação das mulheres em atividades rentáveis não garante a elas uma mudança de valores, símbolos e ideias referentes ao papel que representam na família, mas permanece a busca pela conciliação de uma nova atividade ao trabalho doméstico e ao cuidado com os filhos. Algo próprio da divisão sexual do trabalho que considera esse tipo de atividade como próprio das mulheres. Mesmo quando realizam atividades na lavoura elas são caracterizadas como "leves" e ou "ajuda".

As diferenciações dessas atividades exercidas pelos membros das famílias são assim descritas pela participante da pesquisa:

Aqui a gente é que cuida do serviço da casa, os homens nem encostam, mas na hora da lida na roça a gente ajuda. Aqui na cerâmica também eles fala que é serviço de mulheres, os meninos que querem aprender são poucos e nem vai muito pra frente (informação verbal) ${ }^{3}$.

A gente faz o trabalho de casa e ajuda na roça, levanta todo mundo junto e vai pra roça, pra lida. Eu e os meus filhos ajuda o meu marido, mas o serviço pesado é ele que faz, ele que sustenta a casa" (informação verbal $)^{4}$.

\footnotetext{
${ }^{3}$ Entrevista realizada com Joana, na comunidade de Itamatatiua, em junho de 2017.

${ }^{4}$ Entrevista realizada com Luiza, na comunidade Itamatatiua, em agosto de 2017.
} 
O trabalho feminino, nesse contexto, torna-se um conjunto de atividades invisíveis, estritamente vinculadas ao labor doméstico. As agricultoras familiares realizam atividades produtivas, como o plantio e a colheita da produção para o autoconsumo da família, o cuidado com animais domésticos, o cultivo da horta e, também, práticas orientadas para a pequena escala de comercialização de produtos agrícolas, embora suas presenças na produção agrícola não sejam consideradas como trabalho. Para Schneider (2005), parte dos estudos sobre mulheres rurais realizados no Brasil manteve sempre a tendência de considerá-las a partir de seu lugar dentro da unidade de produção, focalizando sua condição de trabalhadoras não remuneradas e com baixa valorização.

Nas últimas décadas, a visibilidade das agricultoras familiares rurais tem sido marcada por um forte caráter reivindicativo, que se articula com a luta pela terra. Nesses processos, elas vivenciam formas específicas de opressão, próprias à condição de gênero. No entanto, ao questionarem a estrutura hierarquizada do movimento sindical, ampliam a luta política por igualdade de gênero. $\mathrm{O}$ desdobramento dessas lutas foi vital para a conquista do direito de sindicalização, conforme relata uma das lideranças da comunidade de Agrovila:

Oh aqui os papéis que mais se destaca são das mulheres. No caso a presidenta da associação é mulher né, antes era homem agora já é mulher, a questão da igreja é mais mulher que fica nessa parte, na escola nossas mulheres tem bastante participação (informação verbal) ${ }^{5}$.

Essas lutas travadas nos espaços doméstico/familiar, nos movimentos sociais, ou nas arenas de participação política e social, instituídas pelo Estado como poder político, permitem formas de participação mais ativa, seja na construção de associações e/ou cooperativas, seja em experiências de produção e comercialização de produtos agrícolas, extrativistas, pesca e artesanato no mercado capitalista. Apesar da pouca visibilidade das mulheres, inclusive nas suas próprias organizações, já que a expressão da divisão sexual do trabalho que permeia a sociedade também faz parte do meio rural, as agricultoras estão inseridas nesses espaços da sociedade civil, construindo redes de economia solidária e produção agroecológica. É assim que Marta caracteriza a sua vivência na organização que participa:

Fazemos parte do sindicato, ajuda muito porque a gente fica por dentro de tudo, senão somos esquecidas. No meu caso, faço as polpas de fruta

\footnotetext{
${ }^{5}$ Entrevista realizada com Isadora, na comunidade de Agrovila, em agosto de 2017.
} 
no meu sítio, uma produção caseira, me auxilia muito porque compartilhamos muitas coisas (informação verbal) ${ }^{6}$.

Ainda foi possível observar na comunidade de Agrovilas, por meio do Projeto Agrovilas ${ }^{7}$, outras formas de participação das mulheres, sendo uma delas a inserção como militantes ativas da Marcha das Margaridas, evento que envolve diversos outros movimentos sociais do campo, como a Confederação Nacional dos Trabalhadores na Agricultura (Contag) e o Movimento dos Trabalhadores Rurais Sem Terra (MST) entre outros.

Eu acho muito importante as mulheres tá dentro de uma sociedade onde a gente busca nossos objetivos e se empoderar como mulher. Eu acredito que já deixou aquela época da gente ficar encolhida é tempo da gente expandir o que a gente quer dentro da sociedade (informação verbal $)^{8}$.

Essa inserção mostra a preocupação em construir uma identidade política como trabalhadoras rurais. A participação na Marcha das Margaridas também faz parte da estratégia de visibilidade das ações que empreendem. Além disso, contribui para a autonomia e o empoderamento, a mudança de comportamento e a atuação organizada da mulher no meio rural. De certa forma, pode-se considerar que a inserção das trabalhadoras rurais nos movimentos sociais proporciona o amadurecimento destas enquanto sujeitos políticos e sociais, rompendo sua invisibilidade como trabalhadora (ANTUNES, 2006).

Assim, acreditando na potencialidade do espaço que vivem e nas suas histórias de vidas, as trabalhadoras rurais têm se articulado em suas mais diferentes reivindicações, construindo redes de apoio que as proporcionam novas realidades e conquistas.

\footnotetext{
${ }^{6}$ Entrevista realizada com Marta, na comunidade de Agrovila, em fevereiro de 2018.

$7 \mathrm{O}$ projeto Agrovilas tem o intuito de proporcionar às moradoras uma vida saudável mediante a prática de exercícios físicos. O projeto foi construído pelas próprias moradoras da comunidade e conta com o auxílio de um educador físico.

${ }^{8}$ Entrevista realizada com Isadora, na comunidade de Agrovila, em julho de 2018.
} 


\section{Mulheres rurais: as redes de apoio social e a construção do desenvolvimento local sustentável}

Para melhor entender a dinâmica das redes nas comunidades rurais é importante destacar a definição de Castells (1999), segundo o qual as redes trazem uma nova morfologia social que modifica, de forma substancial, a operacionalização e os resultados dos processos produtivos.

Redes são estruturas abertas que tendem se expandir gerando novos nós, que compartilham os mesmos códigos de comunicação. $\mathrm{Na}$ sociedade em rede, há uma primazia da morfologia sobre a ação social, uma espécie de estruturalismo globalista. A lógica de redes gera uma determinação social em nível mais alto que a dos interesses sociais específicos expressos por meio das redes (CASTELLS, 1999, p. 174).

Especificamente nas comunidades rurais, estas podem ser entendidas como articulação entre um conjunto de participantes autônomos que unem ideias e recursos em torno de interesses compartilhados, podendo ser vistos como estruturas menos hierarquizadas e com regras de funcionamento menos rígidas do que em instituições formais. Como ferramentas de organização social, fazem referência às ações de solidariedade (LÓPEZ-CABANAS, 1997). Quanto às redes de apoio social (familiares e vizinhanças), estas se consolidam em momentos de privação social e material, ou, ainda, na organização de mutirões de trabalho, verdadeiros suportes para aliviar a sobrecarga de atividade da dupla jornada de trabalho, comumente experenciados por mulheres no ambiente familiar, laboral e comunitário (MARTELLETO, 2001).

As lideranças assumem posições estratégicas na comunidade, porque se posicionam sobre questões relevantes no que se refere à luta pela reprodução social. As próprias interações que desenvolvem transformam-se em relações de apoio. No caso especifico das comunidades de Itamatatiua e Agrovila, elas intervêm mediando relações de gênero e construção de novas lideranças comunitárias.

Sobre a importância das redes sociais, Bourdieu (2012) traz uma contribuição importante ao afirmar que o capital social representa um conjunto de recursos atuais ou potenciais ligados à posse de uma rede durável de relações, as quais estão mais ou menos institucionalizadas pelo interconhecimento. Em outros termos, é a vinculação a um grupo, como um conjunto de agentes que não somente são dotados de propriedades comuns, mas que são unidos por ligações permanentes e úteis. Esse capital social, baseado na interação dentro de grupos, ou entre grupos, é elemento básico da democracia e da cidadania, sendo capaz de promover a confiança mútua e o desenvolvimento de comunidades. 
Pode ser observado e descrito no diário de campo (DC) o trabalho de cerâmica na comunidade de Itamatatiua e a agricultura de subsistência praticada pelas mulheres, atividades que têm contribuído para autonomia e conquista de espaço, pois, criam, ao mesmo tempo, uma extensa rede de relações e de empoderamento político, assim como a tomada de decisões no contexto familiar, no trabalho e na comunidade.

Nesse sentido, as redes possibilitam que as mulheres, ao exercerem muitas vezes atividades remuneradas fora do âmbito doméstico, acionem a rede de apoio para a realização das atividades domésticas, ou, até mesmo, para ajudar no cuidado com os filhos. Esse aspecto foi verificado quando as mulheres da referida comunidade foram questionadas sobre abrir mão de alguma atividade remunerada por conta do cuidado com a casa ou dos filhos.

Teve uma época que fui fazer um serviço em outro município que era Bacurituba e Cajapió que são bem distante, então tinha que passar a semana toda. Nessa época foi muito difícil porque os meninos estavam muito pequenos, mas ainda bem que tenho uma família que sempre tá apoiando e acabei indo (informação verbal) ${ }^{9}$.

Essas conquistas não eliminam o fato de que as mulheres se tornam lideranças, mas o papel de esposas permanece como a regra. Parece que ao exercerem vários papéis e adentrarem na esfera privada do lar, vão deixando todo o poder alcançado na esfera coletiva, do lado de fora. No entanto, o empoderamento ainda é uma conquista de poucas mulheres e que ganha diferentes contornos relacionados aos elementos políticos, ideológicos e sociais de uma sociedade patriarcal, especialmente no meio rural.

Essa realidade possibilita que as trabalhadoras rurais assumam, cada vez mais, protagonismo e em condições adversas nas quais participam ativamente: "Já trouxemos muitos projetos aqui para a comunidade de Itamatatiua, graças ao artesanato da cerâmica. Esse galpão, a Luz, a água, a pousada. Até o turismo trouxemos aqui para a comunidade" (informação verbal) ${ }^{10}$.

Com reconhecimento do protagonismo das mulheres, o relato da participante apresentado acima revela como as articulações, por meio das redes de apoio, contribuem para a construção do desenvolvimento local sustentável dessas comunidades rurais, mobilizando pequenos grupos no município e na comunidade. O intuito é criar mecanismos de resolução das questões imediatas, como aquelas ligadas à sobrevivência econômica, e construir processos de

\footnotetext{
${ }^{9}$ Entrevista realizada com Mariana, na comunidade de Agrovila, em agosto de 2018.

${ }^{10}$ Entrevista realizada com Marisa, na comunidade de Itamatatiua, em novembro de 2018.
} 
democratização no trabalho, na comunidade e na esfera doméstica. As redes são acionadas como recursos para desenvolver as competências locais, logo, devem ser interpretadas a partir de diferentes ângulos. Aqui a ideia é pensar as redes como estratégia de ação coletiva, objetivando uma transformação social em um determinado local (SCHERER-WARREN, 1999).

É importante reafirmar que o trabalho cooperado possibilita o desenvolvimento individual e comunitário a partir de estratégias de resistências que se constituem como formas de sobrevivência e autonomia. Para isso, é necessário dar visibilidade ao trabalho da mulher no meio rural, tendo em vista uma perspectiva integradora que combina não só o ponto de vista produtivo, mas, também, as dimensões social, ambiental e cultural do trabalho da mulher no meio rural.

Wanderley (2000) analisa o meio rural com esse enfoque de integração, denominado de multifuncionalidade agrícola, vinculado à expectativa de uma agricultura e de um desenvolvimento rural sustentável.

A associação de mulheres uniu muito a gente, até as mulheres mais novas também participam e aprende a fazer as peças de cerâmica, umas vão até tirar o barro no campo, esse é um serviço mais pesado. (informação verbal) $)^{11}$.

Vendo a polpa de fruta pra todo mundo da comunidade e na feira em Pinheiro, gosto do meu trabalho, fui criada na roça, acostumada com essa lida. (informação verbal) ${ }^{12}$.

As mulheres das comunidades de Itamatatiua e Agrovila conseguem se integrar por meio da associação de mulheres, das relações sociais e redes de apoio, da fabricação de artesanatos de cerâmica e produção agrícola, dos valores econômicos, da tradição cultural na manutenção de atividades dos seus descendentes e das ações ambientais no cultivo da terra e no artesanato, com uso racional e ecológico de materiais. Essa realidade condiz com o conceito de desenvolvimento sustentável definido por Sachs (2000), que revela as interdependências entre diferentes dimensões da realidade social e de uma abordagem pluridisciplinar.

Contudo, como pode ser verificado a partir do dado de função das redes e promoção do desenvolvimento discutido por Vachon (2001), as mulheres das comunidades estudadas conseguem aproveitar mais racionalmente os recursos disponíveis; geram economia de tempo que resulta da partilha da reflexão e favorece a implantação de um número maior de projetos; permitem acelerar os

\footnotetext{
11 Entrevista realizada com Fabiana, na comunidade de Itamataiua, em agosto de 2018.

${ }^{12}$ Entrevista realizada com Marta, na comunidade de Agrovila, em julho de 2018.
} 
processos de desenvolvimento local, indo além das ações pontuais. Esses processos têm ocorrido tanto na comunidade de Itamatatiua quanto em Agrovila a partir da imensa rede de parentesco, amigos e contatos formados nas comunidades e, algumas vezes, externamente aos grupos locais. Os campos de contatos são compostos, geralmente, por membros da família mais próximos, vizinhos e amigos. É comum que estes trabalhem na lavoura, na confecção de cerâmica e na comercialização dos produtos.

Enquanto em Itamatatiua, na fabricação da cerâmica, as mulheres participam da produção e comercialização dos produtos, contribuindo para a dinamização da atividade econômica da região e complementação da renda familiar, na comunidade Agrovila, o cultivo agrícola (verduras e frutas) é feito nas feiras dos municípios próximos, retorno financeiro que entra na composição da renda familiar.

É importante ressaltar que essa inserção está apoiada no desenvolvimento das redes de parentesco, cuja base é a cooperação. Nesse trabalho de produção e comercialização, cada um exerce uma atividade específica, mas em cada etapa prevalece o espírito de comunidade, o que leva a pensar, segundo análise de Mocellim (2011), que a comunidade é um lugar onde são compartilhados valores e visões de mundo.

Nesse sentido, pode-se afirmar que a existência de relações comunitárias associativas, como bem enfatiza Weber (2015), constitui uma relação social, uma "relação associativa", já que a ação social repousa num ajuste e união de interesses racionalmente motivados (com referência a valores ou fins). A existência dessas redes de apoio e do conjunto de relações desenvolvidas no interior das comunidades com outras mulheres minimiza a sobrecarga do trabalho exercido e permite que as mesmas transitem em outros espaços de convivência. É assim que Eloisa descreve a rotina de trabalho na fábrica de cerâmica:

$\mathrm{Na}$ fabricação das peças cada uma tem a sua função, as suas peças que fabrica, mas pra vender é tudo junto, depois distribuímos o dinheiro. Tem uma responsável pela contabilidade, outra na venda, outras que vão para as feiras de exposição e assim vai (informação verbal) ${ }^{13}$.

Identifica-se, principalmente, a relação de parceria entre as famílias no trabalho e para o trabalho, o que resulta num efeito sistêmico desses arranjos familiares por meio das redes sociais de apoio, onde cabem estratégias e articulações que garantem a sobrevivência integrada de todos. Como se pode verificar nos dados da entrevista semiestruturada, esses vínculos criam laços de amizade e se

\footnotetext{
${ }^{13}$ Entrevista realizada com Fabiana, na comunidade de Itamatatiua, em novembro de 2018.
} 
solidificam. É o que Silva et al. (2010) assinalam como sendo condicionamentos à formação de vínculos sociais que asseguram a proteção de todos os membros familiares e geram novos vínculos, os quais podem ser utilizados em situações de dificuldades.

A pretensão, aqui, é relacionar as redes de apoio mantidas pelas mulheres e suas consequências positivas para o desenvolvimento local sustentável das comunidades estudadas. A análise realizada por Andion (2003) sobre a relação entre a prática do desenvolvimento local sustentável e o funcionamento de redes fornece pistas para se compreender a dinâmica das redes, suas dimensões e variáveis multidimensionais, dentro de sua complexidade. Isto é, as redes como sistemas privilegiados de gestão e de concretização do desenvolvimento local sustentável.

Os vínculos constituídos nas redes de apoio social dão sustentabilidade ao desenvolvimento de atividade do trabalho remunerado, pois é necessário à família manter as interações internas, participar de diferentes subsistemas familiares, contextos e grupos extrafamiliares. Como aglomerados familiares, mantêm-se unidos não apenas por uma questão afetiva, mas por uma dependência mútua, a qual, por sua vez, assegura a reprodução do grupo e o desenvolvimento sustentável das comunidades.

\section{Considerações finais}

Percebe-se que as experiências das comunidades estudadas implicam tanto transformações no âmbito doméstico quanto o surgimento de novas condições de inserção nos espaços de trabalho produtivo, estabelecendo uma nova reintegração entre o público e o privado, o que pode favorecer os processos de transformações nos territórios que essas mulheres ocupam. Apesar do aspecto de desvalorização do trabalho feminino, constatou-se, durante a pesquisa, que os posicionamentos da mulher na estrutura familiar e no contexto do trabalho associativo são considerados dinâmicos e abrange um aglomerado de sistemas que mantêm relações interdependentes entre si.

Nesse sentido, o contexto social atua como facilitador do desenvolvimento, produzindo mudanças na própria inserção das trabalhadoras rurais, pois existe uma interação dinâmica e recíproca entre a casa e o meio rural como local de trabalho. Essa dinâmica inclui características de desenvolvimento local sustentável, para o qual as mulheres rurais participam ativamente.

O próprio movimento no espaço ecológico e a relação estabelecida entre a família, o trabalho e a comunidade levam ao exercício de novos papéis. Logo, a reorganização de novas redes sociais de apoio, tecidas a partir de relações de 
parentesco e de vizinhanças, contribui para a transformação da situação de vulnerabilidade social e inclusão das comunidades rurais estudadas.

Constata-se, por fim, que este trabalho pode ser útil para a compreensão dos efeitos de políticas públicas, pois foi possível pensar as relações entre as redes de apoio social e a participação das mulheres e suas lideranças nas atividades envolvidas, com exploração de diversos aspectos para o desenvolvimento local sustentável. Essas análises poderiam contribuir para uma maior compreensão sobre a participação das mulheres no desenvolvimento rural, apontando para uma proposta com bases democráticas e sustentáveis do desenvolvimento das ações comunitárias e do trabalho na lavoura e na produção do artesanato de cerâmica.

\section{Referências}

ANDION, Carolina. Análise de redes e desenvolvimento local sustentável. Revista de Administração Pública, Rio de Janeiro, v. 37, n. 5, p. 1033-54, set./out. 2003.

ANTUNES, Marta. As guardiãs da floresta do babaçu e o tortuoso caminho do empoderamento. In: WOORTMANN, Ellen F.; MENACHE, Renata; HEREDIA, Beatriz (Org.) Margarida Alves: coletânea sobre estudos rurais e gênero. Brasília: MDA, 2006.

ANDRADE, Manuel Correia de. Paisagens e problemas do Brasil. 2. ed. São Paulo: Brasiliense, 1969.

ALMEIDA, Lúcio Flávio Rodrigues de. Lutas sociais, direitos e políticas públicas. Revista de Políticas Públicas, São Luís, v. 9, n. 1, p. 279-302, jul./dez. 2005.

ARENDT, Hannah. A condição humana. Trad. Roberto Raposo. 7 ed. Rio de Janeiro: Forense Universitária, 1995.

BARBOSA, Zulene. Maranhão, Brasil: lutas de classes e reestruturação produtiva em uma nova rodada de transnacionalização do capitalismo. São Luís: EDUEMA, 2006.

BOURDIEU, Pierre. O poder simbólico. 16 ed. Rio de Janeiro: Bertrand Brasil, 2012.

CASTELLS, Manuel. A sociedade em rede. São Paulo: Paz e Terra, 1999. 
GRIJÓ, Wesley Pereira. Comunicação e cultura: a comunicação oral como instrumento de construção da identidade negra. In: Congresso de Ciência da Comunicação na Região Centro-Oeste, 9., 2008, Dourados. Anais [...]. Dourados: INTERCOM, $2008 . \quad$ Disponível em: <http://www.intercom.org.br/papers/regionais/centrooeste2008/resumos/R110144-1.pdf>. Acesso em: 10 ago. 2019.

HEREDIA, Maria Alásia; CINTRÃO, Rosângela Pezza. Gênero e acesso a políticas públicas no meio rural brasileiro. Revista Nera, Presidente Prudente, v. 9, n. 8, p. 1-28, 2006.

IBGE. Sinopse preliminar do censo demográfico. Rio de Janeiro: Instituto Brasileiro de Geografia e Estatística, 2015.

LÓPEZ-CABANAS, Miguel. Apoyo social, redes sociales e grupos de autoayuda. In: LÓPEZ-CABANAS, M.; CHACÓN, F. (Org.) Intervención psicosocial y servicios sociales: un enfoque participativo. Madrid: Síntesis Psicológica, 1997.

MARTELLETO, Regina Maria. Análises de rede sociais: aplicação nos estudos de transferência de informação. Ciência da Informação, Brasília, v. 30, n. 1, p. 71 81, jan./abr. 2001.

MOCELLIM, Alan Delazeri. A comunidade: da sociologia clássica à sociologia contemporânea. Revista do Programa de Pós-Graduação em Sociologia da USP, São Paulo, v. 17, n. 2, p. 105-125, 2011.

PEREIRA Jr., Davi. Tradição e identidade: a feitura de louça no processo de construção de identidade da comunidade de Itamatatiua, Alcântara/Maranhão. In: MARTINS, C. C.; CANTANHÊDE Fo., A.; GAIOSO, A. V.; ARAÚJO, H. F. A. (Org.) Insurreição de saberes: práticas de pesquisa em comunidades tradicionais (interpretações do Maranhão). Manaus: Universidade do Estado do Amazonas, 2011, p. 20-52.

SACHS, Ignacy. Caminhos para o desenvolvimento sustentável. Rio de Janeiro: Garamond, 2000.

SCHERER-WARREN, Ilse. Cidadania sem fronteiras: ações coletivas na era da globalização. São Paulo: Hucitec, 1999.

SCHNEIDER, Sergio. As formas sociais do trabalho no meio rural: a pluriatividade e as atividades rurais não agrícolas. Revista Redes, v. 9, n. 3, p. 75109, 2005. 
SILVA, Berenice Gomes. A Marcha das Margaridas: resistências e permanências. Resumos das teses e dissertações apresentadas no PPG-SOL/UnB. Sociedade e Estado, Brasília, v. 23, n. 2, p. 487-498, mai./ago. 2008.

SILVA, K. F. Repensando o trabalho feminino no meio rural. In: FERREIRA, Mary (Org.) Mulher, gênero e políticas públicas. Salvador: Redor, 1999.

SILVA, Simone Souza da Costa; PONTES, Fernando Augusto Ramos; LIMA, Leandro Cavalcante; MALUSCHKE, Julia Bucher. Rede social e papéis de gênero de casais ribeirinhos de uma comunidade amazônica. Psicologia: Teoria e Pesquisa, v. 26, n. 4, p. 605-612, 2010.

TEIXEIRA, Marilane Oliveira. Desigualdades salariais entre homens e mulheres a partir de uma abordagem de economistas feministas. Revista Gênero, Niterói, v. 9, n. 1, p. 31-45, 2. sem. 2008.

VACHON, Bernard. Le développement local: théorie et pratique. Montréal: Gaetan-Morin, 2001.

WEBER, Max. Economia e sociedade: fundamentos da sociologia compreensiva. Trad. Regis Barbosa; Karen Elsabe Barbosa. 4 ed. Brasília: Ed. UnB, 2015.

WANDERLEY, Maria de Nazareth Baudel. A emergência de uma nova ruralidade nas sociedades modernas avançadas: o "rural" como espaço singular e ator coletivo. Revista Estudos Sociedade e Agricultura, Rio de Janeiro, v. 8, n. 2, p. 87-145, out. 2000 .

Endereço para correspondência:

Neuzeli Maria de Almeida Pinto - neuzelialmeida@globo.com

Cidade Universitária Paulo VI, s/n

65055-970 São Luís/MA, Brasil

Josilene Montelo Ferreira - josymontelo02@gmail.com

Rua São Pantaleão, s/n - Centro

65014-460 São Luís/MA, Brasil 